\title{
Research Paper: Topics of Disasters in Scientific Outputs of Medical Sciences: A Cross-Sectional Study
}

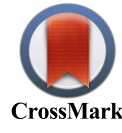

\author{
Zahra Aghalari $^{1}$, Aram Tirgar ${ }^{2 *}$ \\ 1. Student Research Center, Babol University of Medical Sciences, Babol, Iran. \\ 2. Social Determinants of Health Research Center, Health Research Institute, Babol University of Medical Sciences, Babol, Iran.
}

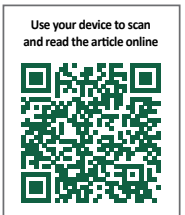

Cittation: Aghalari Z, Tirgar A. Topics of Disasters in Scientific Outputs of Medical Sciences: A Cross-Sectional Study. Health in Emergencies and Disasters Quarterly. 2017; 2(2):47-52. https://doi.org/10.18869/nrip.hdq.2.2.47

: https://doi.org/10.18869/nrip.hdq.2.2.47

\section{Article info:}

Received: 16 Aug. 2016

Accepted: 30 Nov. 2016

\section{Keywords:}

Disasters, Accidents, Medical research, Medical universities

\begin{abstract}
Background: Accurate and timely information plays an important role in disaster preparedness and this information is partly obtained through research and scientific articles. This study aimed to evaluate the publication status of scientific articles about disasters and accidents in Iranian Medical Journals from 2010 to 2015.

Materials and Methods: All Persian articles on the subject of natural disasters; safety; occupational, road, or home accidents, burns, medical errors, related disasters, and emergencies were extracted. The relevant data were collected using a researcher-made checklist through the survey of selected articles.

Results: The results obtained from 36341 articles out of 156 journals published by 47 medical universities showed that $599(1.6 \%)$ articles were related to emergencies, disasters, and accidents, in which 30(0.08\%) articles were about natural disasters and 569(1.5\%) papers were about man-made accidents.

Conclusion: Although, there were scientific articles dedicated to emergencies, disasters and accidents, such topics were limited. Therefore, it seems necessary to take appropriate measures aimed at greater attention to the needs of national and regional medical scientists.
\end{abstract}

\section{Introduction}

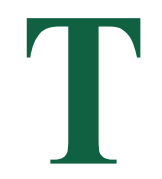

he scientific-research journals in medical universities are considered as the main tool for presenting the results of research in Medical Sciences and Health Studies. Therefore, paying special attention to health-related problems such as accidents and disasters in the medical literature can directly or indirectly represent the scientific community's attention to the needs of society and protection of people's health [1]. Iran is a disaster-prone country which is subject to a variety of disasters. Iran is among 10 accident-prone countries in the world, and despite the science and technology advances, there are shortcomings concerning the effective confrontation with different aspects of disasters and accidents [2, 3]. Out of 40 natural disasters in the world, 31 have so far happened in Iran, which caused many damages $[4,5]$.

Seventy percent of our country is at risk of earthquake, $50 \%$ flood risk, and $90 \%$ of the populations are exposed to risks from floods and earthquakes. In the past seven years, natural

\section{* Corresponding Author:}

Aram Tirgar, PhD

Address: Social Determinants of Health Research Center, Health Research Institute, Babol University of Medical Sciences, Babol, Iran

.E-mail: a.tirgar@mubabol.ac.ir 
disasters have caused more than 2157 billion Rls damage to our country and put Iran in the sixth place in the world according to official statistics of natural disasters $[6,7]$.

Accidents are the major problems related to public health, which annually threaten the lives of many people in developed and developing countries [8]. According to published statistics, injuries due to accidents are among the 5 leading causes of death among different age groups in developed and developing countries. Today, the accidents have become an epidemic problem not only on the road but at home, school, recreation centers, sports arenas and workshops and are also one of the main problems in the industrialized and developing countries [8]. The occupational accidents have also a very effective role in the global burden of diseases. According to the International Labor Organization, 2 million people annually die in work-related accidents and diseases which means one person die every 15 seconds [9]. According to available statistics, occupational accidents are considered as the third cause of mortality in the world [10].

Road, aviation, and rail accidents are other major public health problems in our time so that such accidents can kill 2.1 million people in the world and injure nearly 50 million people [11]. Recent research has shown that $25 \%$ of deaths are caused by traffic accidents [12]. Iran witnessed the death of more than 27000 persons and 276000 injured in the accidents in 2006. According to statistics, an average of 75 persons a day are killed by traffic accidents in Iran, although the figure is about 3000 people per day worldwide. The share of human factor in road accidents is estimated more than $97 \%$ [13]. Most deaths from traffic accidents among young people occur in low and middle-income countries. However, it is predicted that in the ranking table of diseases, road accidents rose from the ninth place in 1990 to the third place in the $2020[14,15]$.

Home accidents are also the most common causes of death and disability in childhood and old age, and 75\% of injuries in persons older than 65 years in industrialized countries [8]. The high mortality rate due to home accidents caused different countries to study demographic characteristics to identify the causes and context of accidents and their prevention programs [16].

Due to the dramatic increase in natural disasters and various events in recent years, unpleasant consequences such as organ failure, disability and death have plagued many demographic groups, including children, adolescents and other vulnerable groups of society. Thus, achieving an acceptable level of health is not possible without serious and practical planning. In this regard, it is necessary to consider the measures appropriate to the circumstances and threats. In this regard, one of the fundamental requirements is providing the necessary information to make these infrastructures. This information can be found by visiting trusted sources, such as scientific and research papers to prepare the health teams based on such information. In other words, research is the main context of a country's progress in different branches of sciences, including medical sciences and medical universities are considered as the main centers of scientific publications in this field.

Given the importance of research about disasters and accidents and also the lack of access to the similar information in this field, we decided to study the status of scientific production in the field of disasters and accidents for a 6-year period among the scientific-research medical journals. We hope that in this way we can investigate the consideration of health and medical professionals about disasters and increase their attention and willingness to research articles related to the disasters and accidents.

\section{Materials and Methods}

This cross-sectional descriptive study was conducted over a 6-year period (from the January 2010 until December 2015) among all the medical journals published by universities of Medical Sciences. Articles were obtained by visiting the website of the medical universities and websites of journals and then their titles, abstracts and keywords were evaluated in terms of addressing the issue of disaster using conventional practices in Scientometrics (A common method of assessing scientific activities and quantification of its development) [17].

In this study, data collection was done through census and using a researcher-made form adjusted to the study purpose. Study variables include universities, science research Persian-language journals in each university, and published articles during 2010-2015; the number of publications was determined with an emphasis on the subjects of natural disasters, safety, occupational accidents, road accidents, domestic accidents, burns, medical and pharmaceutical errors, accidents, and emergencies. It should be noted that the use of these words in the title, abstract, or keywords was the criterion for collecting articles.

During this study, Persian journals that have been translated to English language were excluded, but all the Persian-English journals (with English abstract) were investigated. Journals with unavailable website at the time of the review were excluded, however, their number was very small. For data analysis, descriptive statistics in- 
dexes, including measures of central tendency, as well as tables and graphs were used.

\section{Results}

In the present study, by visiting 47 websites of medical universities, 36341 articles published during 20102015 were investigated, including 156 titles of Persianlanguage scientific-research journals in 3618 issues. In terms of the number of scientific journals, Tehran and Shahid Beheshti Universities of Medical Sciences with 14 Persian journals, and Mashhad and Kerman universities of Medical Sciences (with 8 and 7 journals, respectively) were at the top list of universities in terms of the number of Persian journals.

Among 156 scientific journals, most of them (67.3\%) were directly related to universities and $18.6 \%$ were related to the School of Nursing and Midwifery. Six years follow-up of articles published in medical journals showed that regardless of the increasing frequency and number of journals published in 2015 compared to pre- vious years, the average number of articles in the journals generally increased (Table 1).

Among all reviewed articles and according to the examined parts (title, abstract, and keywords in the subject), 599 articles were identified in relation to accidents and disasters, in which 30 articles were about natural disasters and 569 about man-made disasters.

Out of 599 articles about accidents and disasters, the greatest number of articles (133 cases) was dedicated to occupational safety and then emergencies such as drowning, animal bites, falls in patients and elderly, and medical errors each one with 124 and 95 articles were ranked as the second and third. Figure 1 provides more accurate results regarding topics of research papers. In terms of publication place of these articles, Iran University of Medical Sciences has ranked first with 93 papers and then Tehran and Shahid Beheshti Universities of Medical Sciences each with 86 and 81 articles in the second to third ranks, respectively.

Table 1. Distribution of articles and journals published by Iranian Medical Universities (2010-2015)

\begin{tabular}{|c|c|c|c|c|c|c|c|}
\hline \multirow{2}{*}{ Variable } & \multirow{2}{*}{ Total } & \multicolumn{6}{|c|}{ Publication Year } \\
\hline & & 2010 & 2011 & 2012 & 2013 & 2014 & 2015 \\
\hline Number of journals & - & 94 & 105 & 116 & 157 & 134 & 136 \\
\hline Number of published issues & 3618 & 387 & 486 & 598 & 705 & 716 & 726 \\
\hline Number of published articles & 36341 & 4158 & 5250 & 6194 & 6931 & 6853 & 6955 \\
\hline
\end{tabular}

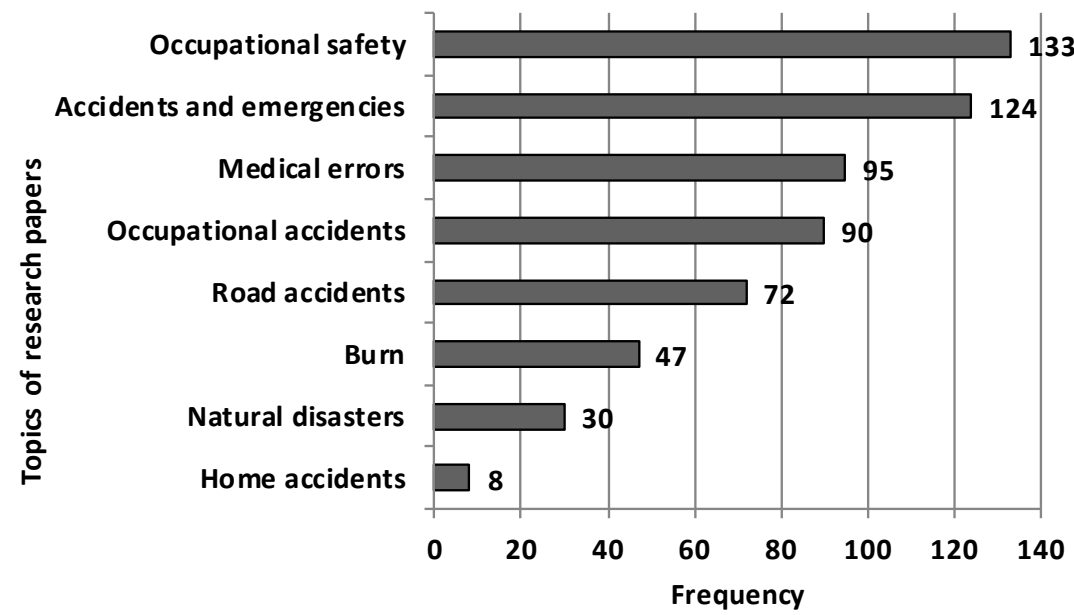

Health in

Health in
Emergencies and |D]isasters [Oluarterly

Figure 1. Distribution of Iranian articles regarding disasters and accidents based on subjects (2010-2015) 


\section{Discussion}

According to the scientific literature, the prevalence of natural disasters in Asia is the highest and Iran is now the fourth country in Asia and the sixth in the world in terms of frequency of natural disasters [18]. Thus the issue of disaster in our country has had a special situation and should be seriously considered because of its high probability of occurrence and unpleasant consequences.

The findings of the present study showed that only 599 articles out of 36000 published articles had the titles related to disaster; this number is the average ratio of about $1 \%$ of the total papers. Therefore, this number is low in term of scientific production, especially in the scientific field related to the disasters and accidents in a country with a high risk of natural disasters. The findings of the present study is consistent with the study of Ostad Taqizadeh et al. (2013) [19].

In this study, the role of new technologies in disaster recovery was examined by articles published in PubMed, Web of Science, and Library of Congress using keywords of rehabilitation, accident, and technology. The results showed that the few papers were published on this topic (21 articles). The few number of articles prompted researchers to examine data sources with the similar related terms such as rehabilitation, in which they found 6 other articles regarding this issue. A total of 27 articles were found on the subject that indicates the lack of attention of the scientific community to the issue of accidents and disasters [19].

Scientific and research articles are the most important tools to represent the research results and they are considered as one of the most important ways to exchange information and experiences among professionals in Medical Sciences. Although in recent years we have observed a growth in the number of publications and articles (respectively $82 \%$ and $60 \%$ rise in the number of publications and papers of Medical Sciences from 2010 to 2015) (Table 1), the few number of published articles about the disasters (only about $1 \%$ of medical articles) indicates a failure in addressing the above issues. Ardalan et al. (2009) in a study on progress and challenges in disaster management in Iran mentioned that Iran gained valuable experiences from multiple disasters such as Bam earthquake and Golestan flood in the past decade; however, disaster management system in the country needs to be strengthened with regard to the inter- and intra-organizational communication and cooperation. Interestingly, they have also called for more research, especially on quality assessment and health management disaster [20].
In another study by Ardalan et al. (2013) on disability and natural disasters in Iran, after referring to 6 scientific databases and review of 13624 scientific documents, only 10 studies were found related to this issue. The results of the study also suggest that there is inadequate scientific and academic evidence on disability and disaster and there is also the need to examine the challenges associated with disability and man-made accidents or disasters [21].

Findings of the present study indicated that out of the total number of 599 articles related to disasters, only 30 articles were associated with natural disasters, while annually about 250 natural hazards occur in our country which left 3000 death, 9000 physical injuries, as well as 5.1 million people affected. The risk from natural hazards in the country (on death) is 8 to 10 . About $97 \%$ of rural homes are not earthquake-resistant and disaster preparedness of households is only $8 \%$ [22].These figures show serious problems in management and information function as well as poor performance of experts against natural disasters. Scientific and educational interventions can increase the readiness of households and also reduce the percentage of deaths and injuries. [23]

It should be noted that part of the disaster research is conducted in other fields such as humanities or engineering. These fields were not the objectives of the present study and of course commenting on those issues requires independent research. So the limitation of the present study can be considered investigating merely medical articles. Furthermore, the 6-year follow-up period is not long enough and it is better to examine this issue for a longer period of time, for example, at least over a 10 -year period.

\section{Conclusion}

In conclusion, despite the crucial role of research as one of the ways to enhance preparedness and response to disasters, and to reduce the damages caused by them, this issue has been rarely examined because the available data in the most and desirable way are not appropriate to the needs of society. Therefore, national research priorities for disaster management should seek mechanisms to encourage medical researchers to study the country and publish more research according to our priorities.

\section{Acknowledgements}

The authors appreciate the cooperation of the members of the Research Center for Social Determinants of Health, and the Deputy for Research and Technology, of Babol University of Medical Sciences for the financial 
support (No. 9236914) and Dr. Evangeline Foronda for editing the manuscript.

\section{Conflict of Interest}

The authors declared no conflicts of interests.

\section{References}

[1] Fereshtehnejad S, Motevalian S, Moradi Lakeh M, Aghili S, Shafiee Sabet A. [Comparison of the qualitative and quantitative indexes of scientific medical journals affiliated to Iran university of medical sciences with Iranian exemplary medical Journals during 2008-2010 (Persian)]. Razi Journal of Medical Sciences. 2010; 17(77):40-54.

[2] Salari A. Health in disasters researches trend in Iran: An overview of the international congress on health and crisis management in disasters. Health in Emergencies and Disasters. 2013; 1(1):54-59.

[3] Vahdati AS, Gholipour C, Talebian MT, Vahdati SS, Mahmoudieh T. Disaster in South-East of Iran: Saravan earthquake with minimum mortality. Journal of Academic Emergency Medicine. 2014; 13(4):216-8.

[4] Kianmehr N, Mofidi M, Nejati A. [Assessment of physician's knowledge about disaster (Persian)]. Journal of Medical Council of Islamic Republic of Iran. 2009; 27(2):184-9.

[5] Vosoughi Niri A, Vosoughi Niri M, Golestani Far H, Pahlovanzadeh B, Savadpoor MT. Investigation of army soldiers readiness about health actions in critical circumstances. Case study: Malek Ashtar Military Garrison's. Health in Emergencies and Disasters. 2013; 1(1):77-87.

[6] Bazregar R, Khankeh H, Ahmadi S, Hosseini M, Rahgozar M, Moradian M. [The evaluation of application of coordination based disaster response model in Rajaye hospital disaster preparedness (Persian)]. Iranian Journal of Nursing Research. 2013; 8(29):10-18

[7] Gharibi F, Kousha A, Farajollah Beiknouri M, Firouz Nia R, Rohani Majd S. [The study of health status in area affected by the earthquake in Azerbaijan through rapid assessment technique in 2012 (Persian)]. Journal of Rescue \& Relief. 2014; 6(1):21-42.

[8] Khosravi S, Ghafari M. [Epidemiological study of domestic accidents in urban and rural area of Shahrekord in 1999 (Persian)]. Journal of Shahrekord University of Medical Sciences. 2003; 5(2):53-64.

[9] Mohammad Fam I, Zokaei H, Simaei N. [Epidemiological evaluation of fatal occupational accidents and estimation of related human costs in Tehran (Persian)]. Journal of Zahedan University of Medical Sciences and Health Services. 2007;8(4):299-307.

[10] Joyani Y, Raadabadi M, Kavosi Z, Sadeghifar J, Momenei $\mathrm{K}$. [Relationship between the occupational accidents and absence from work employees in Shiraz Namazi Hospital (Persian)]. Journal of Payavard Salamat. 2011; 5(3):70-9.
[11] Esmaili A, Azizi HR, Zahiri M. The study of the role of road police in the management of road accidents'scenes (A case study of Ardabil). Traffic Management Studies. 2010; 5(17):1-23.

[12] Pakgouhar A, Khalili M, Safarzadeh M. [The consideration of human factor's role in occurrence and aggravation of road accidents based on the regression models LR and cart (Persian)]. Traffic Management Studies. 2009; 4(13). 49-66.

[13] Fanian MH, Ghadipasha M, Goddousi A, Abedi MH, Farajzadegan Z. [Epidemiologic evaluation of traffic accidents in Isfahan (2002-2003) (Persian)]. Scientific Journal of Forensic Medicine. 2007; 13(2):87-91.

[14] Zarei M, Rahimi-Movaghar V, Saadat S, Panahi F, Dehghanpour R, Samii A, et al. [Road traffic crashes mortality and morbidity in Iran in 1997-2006 (Persian)]. Hakim Research Journal. 2008; 11(3):42-6.

[15] Dianati M, Akbari H. [Epidemiology of home injuries in Kashan during 2005 (Persian)]. Feyz Journals of Kashan University of Medical Sciences. 2009; 12(5):27-32.

[16] Nouhjah S, Ghanavatizadeh A, Eskandri N, Daghlavi M. [Prevalence of non-fatal home injuries and its related factors among children attending health centers in Ahvaz: A pilot study (Persian)]. Hakim Research Journal. 2012; 15(3):238-42.

[17] Tirgar A, Abolghasemi MB, Yaminfirooz M. Citation analysis of graduate dental thesis references: Before and after an intervention. Future of Medical Education Journal. 2013 3(1):2-7. doi: 10.22038/fmej.2013.515.

[18] Sani M. Evaluation of results of natural disaster in America and Iran in the past 100 years. Paper presented at: The $6^{\text {th }} \mathrm{In}$ ternational Congress on Health and Disasters. 2014 February 5-7; Tehran, Iran

[19] Ostad Ta, Latiji Mf, Ardalan A. The role of advanced technologies in disasters recovery and rehabilitation. Paper presented at: The $6^{\text {th }}$ International Congress on Health and Disasters. 2014 February 5-7; Tehran, Iran.

[20] Ardalan A, Masoomi G, Goya M, Ghaffari M, Miadfar J Sarvar M, et al. Disaster health management: Iran's progress and challenges. Iranian Journal of Public Health. 2009; 38(Suppl 1):93-7.

[21] Ardalan AS, Sohrabizadeh M, Delkhosh, Mousavi Gh. Research on disability and natural disasters in Iran: A systematic review. Paper presented at: The $6^{\text {th }}$ International Congress on Health and Disasters. 2014 February 5-7; Tehran, Iran.

[22] Ardalan A. HY, N. Rouhy, and A. Mohammadi. Why management and disaster risk reduction in the field of public health need to develop and strengthen? Paper presented at The $6^{\text {th }}$ International Congress on Health and Disasters. 2014 February 5-7; Tehran, Iran.

[23] Tirgar A, Samaei SE. Systematic analysis of a decade of occupational health research in Iran. Journal of Occupational Hygiene Engineering. 2016; 3(2):47-55. doi: 10.21859/johe03027 
